\title{
Machen Sie den BVG-Check-up!
}

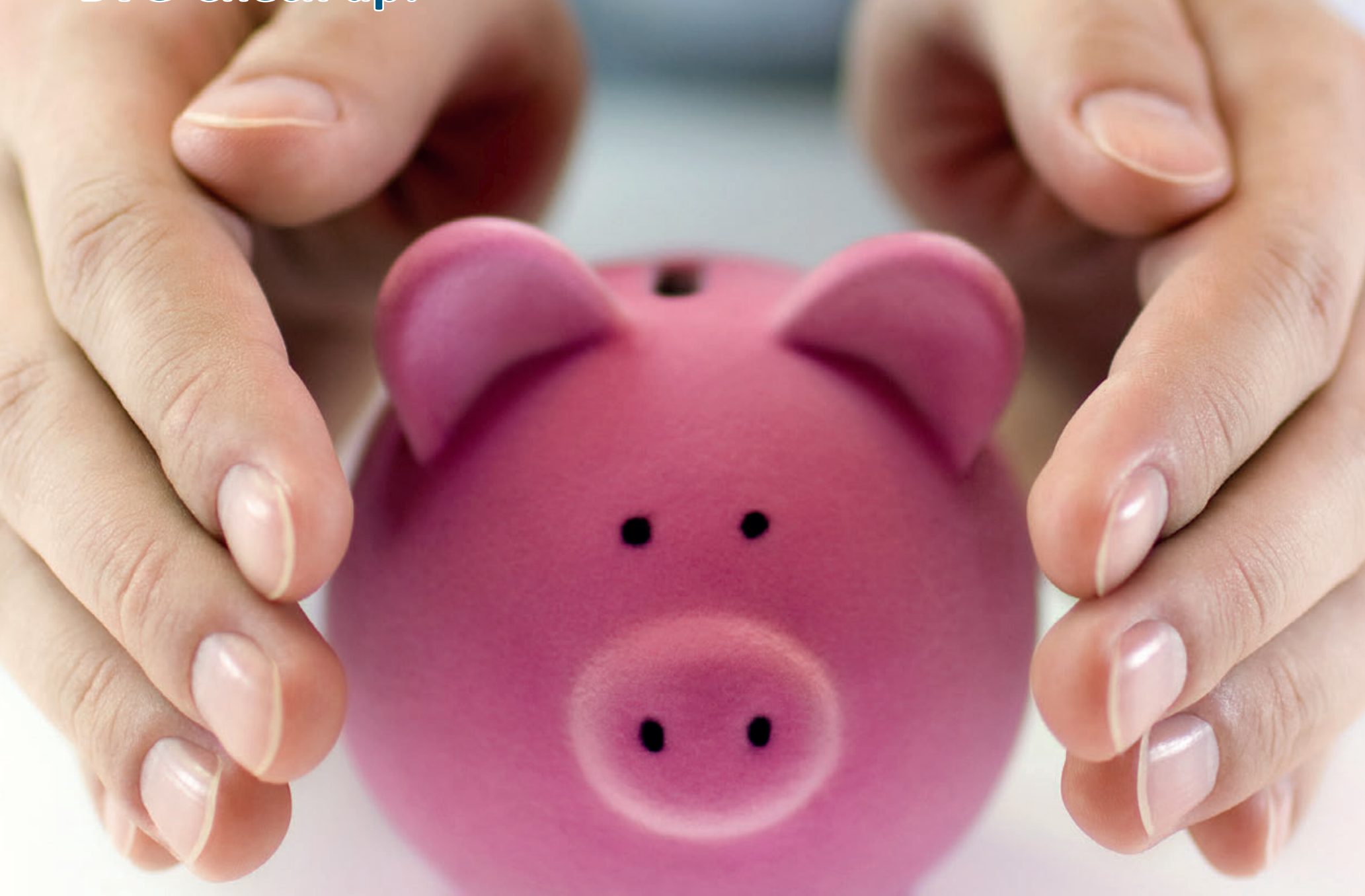

Obwohl der grösste Teil des Privatvermögens der Ärzteschaft bei einer Pensionskasse liegt, wird dieser Bereich oft vernachlässigt. Durch eine regelmässige Überprüfung, wird die gewählte Lösung an die persönliche Vorsorge- und Anlagestrategie angepasst. Ein weiteres Ziel ist es, die Steuersituation zu optimieren. Profitieren Sie dabei von unserer Dienstleistung BVG-Check-up und lassen Sie sich von einem Vertrauenspartner FMH Services (Insurance) beraten.

\section{BVG-CHECK-UP}

\section{FMHSERVICES}

Ich möchte mich unverbindlich beraten lassen. Bitte nehmen Sie mit mir Kontakt auf, um einen Termin zu vereinbaren.

$\square \quad$ Bitte senden Sie mir eine kostenlose Vergleichsofferte zu. (Bitte Kopie des aktuellen Vorsorgeausweises beilegen.)

$\square \quad$ Ich wünsche eine persönliche Beratung. Bitte rufen Sie mich an.

Vorname / Name

Adresse

PLZ / Ort

Telefon Privat / Geschäft

Beste Zeit für einen Anruf

E-Mail-Adresse

\section{INSURANCE}

\section{Roth Gygax \& Partner AG}

Moosstrasse 2, 3073 Gümligen

Tel. 0319595000 - Fax 0319595010

mail@fmhinsurance.ch - www.fmhinsurance.ch

Die Roth Gygax \& Partner AG ist ein von der FMH Services

Genossenschaft empfohlenes, rechtlich und wirtschaftlich selbstständiges Beratungsunternehmen. 